\title{
Estudo das Condições de Saúde e Segurança do Trabalho (SST) em Laboratório de Pesquisa de Tecnologia Ambiental
}

\author{
Study of Health and Safety Conditions \\ (SST) in Environmental Technology Research Laboratory
}

\author{
Marcos Geppert \\ Universidade Federal do Rio Grande do Sul - UFRGS \\ geppert@enq.ufrgs.br
}

Luis Renato Balbão Andrade

Universidade Federal do Rio Grande do Sul - UFRGS

luis.andrade@fundacentro.org.br

Marcelo Pereira da Silva

Universidade Federal do Rio Grande do Sul - UFRGS

ergocelo@gmail.com

Fernando Gonçalves Amaral

Universidade Federal do Rio Grande do Sul - UFRGS

amaral@producao.ufrgs.br

\section{Resumo}

Diversas tecnologias auxiliam na melhoria da produtividade, na ergonomia, no ambiente de trabalho e, principalmente, na logística interna do processo produtivo de um posto de trabalho. Este estudo envolve as definições de ergonomia relacionando-as às considerações sobre gestão de Saúde e Segurança do Trabalho (SST) com ênfase no planejamento tecnológico. Buscou-se, através dos conceitos metodológicos abordados por Guérin et al. (2010), realizar uma análise ergonômica do posto de trabalho de um Laboratório de Tecnologia Ambiental, que se utiliza de processos biotecnológicos, em uma instituição de ensino superior, fazendo-se o mapeamento do sistema e processo alvo e, consequentemente, a análise em função do tempo de operação de um aparelho espectrofotômetro (UV/VIS). Ressalta-se que foi utilizado o instrumento descritivo e qualitativo de observação livre ou direta (in loco) preconizado por Gil (1999) e Diagnóstico Participativo dos Riscos - método DEPARIS do autor Malchaire (2003), com intuito de analisar a atividade prescrita pelos Procedimentos Operacionais Padrão (POP) bioquímicos realizados em peixes Danio Rerio e a desenvolvida na situação real de trabalho. Nesse posto, analisaram-se as tarefas que são executadas pelos profissionais com esses peixes, as consequências do trabalho sobre esses laboratoristas, os métodos de realização desse trabalho e as condições físicas, fisiológicas e psicossociais dos trabalhadores (possíveis riscos ocupacionais). A análise dos resultados serviu de base para a formulação do diagnóstico e proposição da intervenção para melhoria do posto em estudo. Sugere-se a elaboração de um caderno de recomendações de melhorias.

Palavras-chave: SST, Ergonomia, Laboratório de tecnologia ambiental e bioquímica.

\footnotetext{
${ }^{*}$ RECEBIDO EM 02/11/2019. ACEITO EM 03/10/2020.
} 


\begin{abstract}
Various technologies help improve productivity, ergonomics, work environment and, especially, the internal logistics of the productive process of a job. This study involves the definitions of ergonomics relating them to considerations about Occupational Health and Safety (OHS) management with an emphasis on technological planning. It was sought, through the methodological concepts approached by Guérin et al. (2010), to perform an ergonomic analysis of the work of an Environmental Technology Laboratory, which uses biotechnological processes in an institution of higher education, mapping of the target system and process and, consequently, the analysis according to the operating time of a spectrophotometer (UV/VIS) apparatus. It should be emphasized that the descriptive and qualitative instrument of free or direct observation (in loco) Gil (1999) and Participatory Diagnosis of Risks - the DEPARIS method of the author Malchaire (2003), was used to analyze the activity prescribed by the Standard Operating Procedures (SOPs) made in fish Danio Rerio and the one developed in the real work situation. In this position, the tasks performed by professionals with these fishes, the consequences of the work on these laboratories, the methods of carrying out the work, and the physical, physiological and psychosocial conditions of the workers (possible occupational risks) were analyzed. The analysis of the results served as a basis for the formulation of the diagnosis and proposition of the intervention to improve the workstation under study. It is suggested that a book of recommendations for improvement be drawn up.
\end{abstract}

Keywords: OHS, Ergonomics, Environmental Technology and Biochemistry Laboratory. 


\section{Introdução.}

A Ergonomia é derivada no sentido etimológico das palavras gregas ergon (trabalho) e nomos (normas, regras, leis) (DUL; WEERDMEESTER, 2012, p. 13). Segundo Santos \& Fialho (1997, p. $31)$, o verbo "trabalhar" vem do latim popular tripaliare e significa torturar com o tripalium.

Para Schreiner et al. (2008), um laboratório é uma sala ou espaço físico normalmente equipado com diversos instrumentos, onde se realizam experimentos, cálculos, análises e medições, em que trabalham pesquisadores. Nesse contexto, Burmann (2008) e Mente (2007) estudaram um modelo ergonômico de Gestão Participativa em Saúde e Segurança do Trabalho (SST).

Conforme a Associação Brasileira de Ergonomia - ABERGO (2000), a Ergonomia pode ser definida como: "uma disciplina científica relacionada ao entendimento das interações entre os seres humanos e outros elementos ou sistemas, e à aplicação de teorias, princípios, dados e métodos a projetos a fim de otimizar o bem-estar humano e o desempenho global do sistema"

De acordo com a Norma Regulamentadora NR 17, a Análise Ergonômica do Trabalho (AET) tem como objetivo, rastrear, observar e avaliar as relações existentes entre demandas de doenças, acidentes e produtividade com as condições de trabalho, com as interfaces, com os sistemas e a organização do trabalho (MINISTÉRIO DO TRABALHO E EMPREGO, 2002).

Justifica-se a motivação para o tema pela importância da AET em diversas aplicações e escalas, devendo essa abordar no mínimo as condições de trabalho, conforme estabelecido na NR 17. Assim, tem relevância à medida que esse utiliza o princípio da participação, o que motiva para pesquisas de análise ergonômica da situação de trabalho (prescrito $=$ tarefa $\mathrm{x}$ real $=$ atividade) $\mathrm{e}$ a possível elaboração de um futuro caderno de recomendações. Segundo Amaral (2020), não existe um método de análise que seja universalmente adotado e normalizado.

Este estudo visa a apresentar uma análise ergonômica de um posto real de trabalho (AET) de um Laboratório de Tecnologia Ambiental, acompanhando a rotina diária de operadores de um aparelho espectrofotômetro (UV/VIS). Assim, este trabalho constitui-se em uma pesquisa descritiva qualitativa, que analisa variáveis entre o homem e o ambiente, onde está inserido. Ainda, tem por objetivo identificar os pontos específicos que necessitam de melhorias do ponto de vista da Ergonomia, por meio de sugestões colhidas junto aos laboratoristas e coordenadora desse posto e, por fim, apresentar-se propostas de melhorias na ergonomia e SST do ambiente analisado.

Esta pesquisa, utilizou-se do método de observação livre ou direta (in loco), conforme Gil (1999) e do instrumento de Diagnóstico Participativo dos Riscos - método DEPARIS de Malchaire (2003).

Nesse posto, analisaram-se as tarefas a serem executadas pelos colaboradores do laboratório de uma instituição de ensino superior, as consequências das atividades, a metodologia de execução das tarefas e as condições físicas / fisiológicas e ambiente psicossocial desses trabalhadores. A demanda para a AET deve-se especificamente devido a queixas de desconforto dos técnicos de laboratório com o uso de pipetas volumétricas manuais e cubetas no aparelho supracitado.

\section{Fundamentação Teórica.}


Neste item, são apresentados fundamentos teóricos relevantes para o desenvolvimento do presente estudo, como a organização do trabalho, NR 17, Participação e Princípio da Precaução, Metodologia da AET, Diagnóstico e Recomendações com foco na Ergonomia.

\subsection{Abordagens acerca da Ergonomia e suas modalidades.}

Para Wisner (1987), "Ergonomia é o conjunto de conhecimentos científicos relativos ao homem e necessários à concepção de instrumentos, máquinas e dispositivos que possam ser utilizados com o máximo de conforto, segurança e eficiência”. Já Couto (1995) define Ergonomia nas seguintes cinco palavras: adaptação do trabalho às pessoas.

Segundo Iida (2005), a Ergonomia é apresentada através das modalidades de concepção que está relacionada ao estudo ergonômico de instrumentos e ambientes de trabalho, anteriormente a sua construção; de correção que tenta melhorar as condições de trabalho já existentes e a de conscientização que tem por finalidade conscientizar os colaboradores, através de treinamento, reciclagens para trabalharem de forma segura, evidenciando os fatores de riscos para sua saúde mental e física, que podem surgir a qualquer momento no ambiente de trabalho.

Para ABERGO - Associação Brasileira de Ergonomia (2000), de maneira geral, um domínio de especialização da ergonomia é a Ergonomia física que está relacionada com as características da anatomia humana, antropometria, fisiologia e biomecânica em sua relação à atividade física. Os tópicos relevantes desse domínio incluem o estudo da postura no trabalho, manuseio de materiais, movimentos repetitivos, distúrbios músculo-esqueletais relacionados ao trabalho, projeto de posto de trabalho, segurança e saúde.

2.2. Norma Regulamentadora sobre Ergonomia - NR17, Participação e Princípio da Precaução.

A NR17 da Portaria 3.214/1978 do MTE, visa a estabelecer parâmetros que permitam adaptar as condições de trabalho, incluindo aspectos relacionados ao levantamento, transporte e descarga de materiais, ao mobiliário, aos equipamentos e às condições ambientais do posto de trabalho e à própria organização do trabalho (MINISTÉRIO DO TRABALHO E EMPREGO- MTE).

Essa mesma Norma não trata da caracterização de insalubridade, mas estabelece as condições ambientais necessárias para que o trabalho possa ser realizado, sob critérios de segurança e conforto (GUIMARÃES, 2006, p. 3).

Santos \& Fialho (1997, p. 265) salientam que a análise ergonômica do trabalho é uma ferramenta capaz de permitir uma gestão mais participativa, onde o pessoal de nível gerencial deve observar e consultar o pessoal de nível operacional antes de tomar uma decisão técnica ou organizacional, evitando assim as gritantes diferenças que normalmente existem entre o trabalho prescrito e o trabalho real.

Para Andrade (2013, p.105), a condução do controle ou mitigação dos riscos oriundos da nanotecnologia passa pela ampla participação de todos envolvidos em um posto de trabalho.

Segundo Guimarães (2006), a NR-17, como todas as normas, não consegue oferecer respostas para todas as situações encontradas na prática. Cabe salientar que, conforme Andrade (2013, p. 95), o Princípio da Precaução é importante para que não se repitam com as Nanotecnologias, histórias de exposição e adoecimento como as acontecidas com as de asbesto/amianto. Esse mesmo autor salienta 
que os nanotubos de carbono apresentam em alguns casos formato semelhante às fibras do asbesto. Teme-se, assim, que essas nanopartículas possam ser cancerígenas (ARCURI \& PONTES, 2018).

\subsection{Análise Ergonômica do Trabalho (AET).}

Nos projetos de sistemas de produção, a Ergonomia faz convergir os aspectos de segurança, desempenho e qualidade de vida, através de sua metodologia específica, a análise ergonômica do trabalho - AET (ABERGO, 2000).

Para Hormain (2001), a gestão da qualidade só evolui se houver gestão das normas de vida humana, que é a essência da qualidade de vida.

Segundo Balbinotti (2003, p. 48), a AET é uma ferramenta básica no funcionamento e gestão de uma empresa ou instituição. Seus resultados permitem ajudar na concepção efetiva dos meios materiais, organizacionais e de formação, auxiliando o alcance dos objetivos planejados, com a preservação do estado físico, psíquico e vida social do trabalhador. Para o autor, a finalidade da AET é a possibilidade de compreender o trabalho e, a partir dessa compreensão, transformar as situações de trabalho, tendo como parte central a análise da atividade desenvolvida.

A Análise Ergonômica do Trabalho (AET) é fundamentada na forma como o operador trabalha os modos operatórios (modus operandi) para alcançar as finalidades impostas pela organização do trabalho (VIDAL, 2002).

"Uma análise ergonômica deve ter como objetivo a expressão dos trabalhadores sobre suas condições de trabalho. Para transformá-las positivamente é preciso agir, quase sempre, sobre a organização desse trabalho" (GUÉRIN et al., 2001, p. 74).

Segundo o mesmo autor, Guérin et al. (2001, p. 1), para que a ação ergonômica obtenha êxito, é preciso que todos os atores envolvidos na empresa ou instituição participem de todas as etapas do estudo, da direção aos operadores de produção. Para isso, segundo os autores, é necessário aplicar métodos e técnicas para condução das transformações necessárias.

Transformar o trabalho é a finalidade precípua da ação ergonômica. Essa transformação deve ser realizada de forma a contribuir para que a concepção de situações de trabalho não altere a saúde dos operadores, exercendo suas competências, possibilitando a valorização de suas capacidades e alcançando os objetivos econômicos determinados pela empresa ou instituição (GUÉRIN et al. 2001, p. 1).

Para Iida (2005, p. 60), “o método AET tem cinco etapas: análise da demanda, análise da tarefa, análise da atividade, diagnóstico e recomendações". Dessas cinco etapas, as três primeiras constituem a fase da análise e permitem realizar o diagnóstico para formular recomendações ergonômicas. Assim, a seguir, tem-se uma descrição sucinta sobre o que comportam essas três fases do estudo ergonômico do posto de trabalho.

\subsubsection{Análise da demanda.}

Nessa fase, é definido o problema a ser estudado, a partir do ponto de vista dos diversos atores sociais envolvidos (SANTOS \& FIALHO, 1997, p. 55). 
De acordo com Iida (2005, p. 60), Demanda "é a descrição de um problema ou uma situação problemática, que justifique a necessidade de uma ação ergonômica". Já para Guérin et al. (2001, p. 87) tal fase pode ter diversas origens, tanto por parte da direção da empresa ou instituição, como por parte dos trabalhadores e suas organizações sindicais. A análise da demanda procura compreender a natureza e a dimensão dos problemas apresentados.

\subsubsection{Análise da tarefa.}

Nessa fase, são analisadas as condições ambientais (espaço e planos de trabalho, ambiente térmico, ambiente acústico, ambiente luminoso, ambiente vibratório, qualidade do ar) e condições técnicas / organizacionais de trabalho (IIDA, 2005, p. 198).

Segundo Guimarães (2006, p. 25), "a tarefa é o tipo, a quantidade e a qualidade da produção por unidade de tempo e os necessários meios para realizá-la, determinada a um posto de trabalho, a um trabalhador ou a um grupo de trabalhadores".

\subsubsection{Análise da atividade.}

Conforme Santos \& Fialho (1997, p. 56), nessa última fase são analisados os comportamentos do ser humano no trabalho (gestuais, informacionais, regulatórios e cognitivos).

Iida $(2005$, p. 61) afirma que "Atividade refere-se ao comportamento do trabalhador, na realização de uma tarefa e refere-se à maneira como o trabalhador procede para alcançar os objetivos que lhe foram atribuídos". Para o autor, a atividade é influenciada por fatores internos e externos. Os fatores internos localizam-se no próprio trabalhador. Os fatores externos referem-se às condições em que a atividade é executada. Classificam-se em três tipos principais: conteúdo do trabalho (objetivos, regra e normas), organização do trabalho (constituição de equipes, horários, turnos) e meios técnicos (máquinas, equipamentos, arranjo e dimensionamento do posto de trabalho, iluminamento, ambiente térmico) (IIDA, 2005).

Já Guimarães (2006, p. 25) considera Atividade “a ação como é realizada, resultado da união tarefa-indivíduo que a realiza. É como o trabalho real acontece ou se realiza na finalidade proposta, com as formas / condições oferecidas, ao trabalhador ou grupo".

\subsection{Diagnóstico e Recomendações em Ergonomia.}

O diagnóstico procura descobrir as causas que provocam o problema descrito na demanda. Refere-se aos diversos fatores, relacionados ao trabalho e à empresa/instituição, que influem na atividade de trabalho. Por exemplo, acidentes podem ser causados por pisos escorregadios, sinalizações mal interpretadas, manutenção deficiente das máquinas. Outros exemplos: baixa qualidade (devido a erros de projeto), absenteísmos e doenças ocupacionais (provocados por emanação de gases tóxicos) e rotatividade (devido ao treinamento insuficiente) (IIDA, 2005, p. 61).

Ainda para esse autor (2005, p. 62), as recomendações são as providências que deverão ser executadas para resolver os problemas diagnosticados. Têm-se por finalidade propor melhorias, permitindo realizar as atividades com o mínimo de exigências físicas e sem sobrecarga muscular. 


\section{Metodologia.}

O presente estudo serviu-se da metodologia de AET proposta por Guérín et al. (2001) e também com base em pressupostos utilizando-se as dezoito rubricas abordando dezoito facetas da situação de trabalho pela síntese do estudo ou método Diagnóstico PArticipativo dos RIScos - DEPARIS (Malchaire, 2003).

Foram realizadas avaliações com o método de observação livre ou direta (GIL, 1999) com sugestão de melhora do ponto de vista técnico de um posto de trabalho dos colaboradores ou operadores de um aparelho espectrofotômetro UV/VIS e armazenamento de dados necessários para atender à legislação nacional, pertinente a SST em Ergonomia (NR17).

Segundo Gil (1999), a observação é a aplicação dos sentidos humanos para obter determinada informação sobre aspectos da realidade.

Para Guérin et al. (2001, p. 83), “a AET é uma metodologia que possibilita através do ponto de vista da atividade, compreender e correlacionar os determinantes das situações de trabalho com as suas consequências para os trabalhadores e para o sistema de produção".

Conforme Malchaire (2003, p. 20), os trabalhadores são o centro da ação da prevenção, não apenas para dar sua opinião, mas para discutir os detalhes práticos por condições ideais para esses e para a empresa/instituição.

Realizou-se a análise da demanda através de entrevistas e de visitas ao laboratório para levantamento de indicadores de produção, processo e de condições de trabalho (acidentes/incidentes, queixas, entre outros).

Para Bolis (2011), a fase de Análise da tarefa tem como objetivo fazer o levantamento de dados sobre as exigências prescritas da empresa/organização para com seus colaboradores/servidores. Assim, executa-se a análise da tarefa em dois níveis. O primeiro é com relação à descrição do sistema homem-máquina (equipamento) e o segundo do sistema homem-tarefa (IIDA, 2005). Após a seleção da tarefa de pipetagem, passa-se para o estágio de coleta de dados, o qual envolve entrevistas diretas com todos os usuários que a realizam, além de consulta aos coordenadores, para saber exatamente o que é a tarefa prescrita nos POPs e como o trabalhador deve realizá-la (SANTOS \& FIALHO 1997, p. 265).

No posto de trabalho analisado, chegou-se a algumas etapas de que o trabalhador necessita para executá-las. Inicia-se com a leitura do formulário de requisição de análise, atento a todos os detalhes a respeito da cubeta e das características do pipetador. Após, o trabalhador necessita realizar o transporte das amostras até a bancada de trabalho e programar o aparelho espectro UV-Vis para calibração e varreduras. Ao término dessa programação, o servidor pôde completar as cubetas com as amostras, ativando o gatilho do pipetador, fechando o espectrofotômetro e iniciando a leitura absorbância medida. Por último, os técnicos pegam a vidraria, vertem as amostras para frasco de boca larga ou bombona apropriada para descarte de resíduos e lavam essa vidraria (cubetas).

Estruturam-se os procedimentos metodológicos adotados neste trabalho em cinco etapas. A Figura 1 apresenta o resumo da AET e as etapas realizadas. Facilitou-se assim, o entendimento dos procedimentos da pesquisa. 


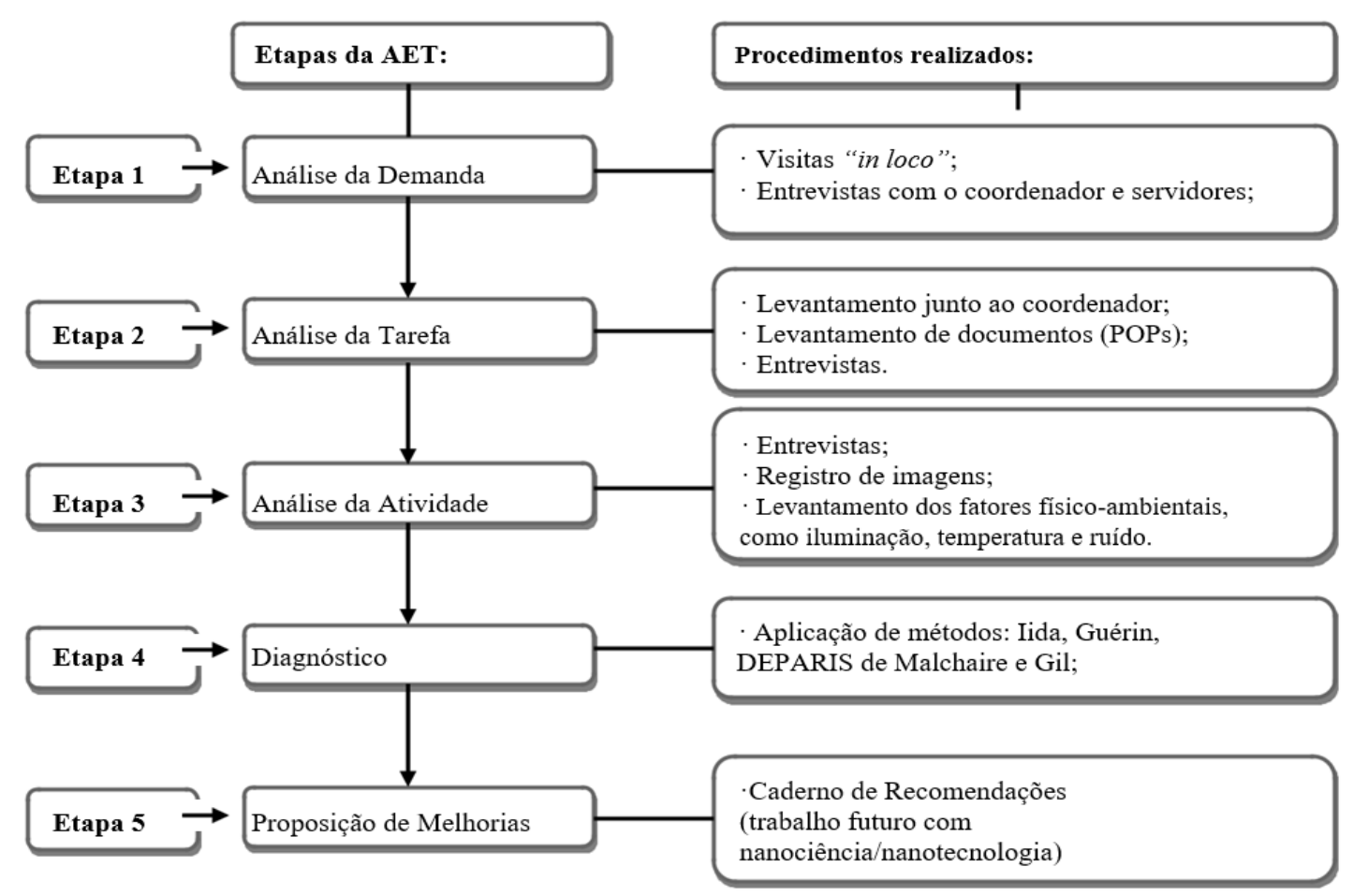

Figura 1 - Procedimentos metodológicos adotados na pesquisa Fonte: Adaptado de Vergara et al. (2016).

\subsection{Análise do Laboratório no seu Contexto das Condições (Técnicas, Econômicas e Sociais) da Situação de Trabalho.}

Os princípios teóricos e metodológicos aqui utilizados foram construídos com referência à metodologia proposta pelos pesquisadores franceses Guérin et al. (2001) e constituem-se em um exemplo de Ergonomia de Correção.

Segundo Abrahão et al. (2009), a necessária linearidade de apresentação da AET não implica na necessidade de que as fases propostas no modelo da Figura 2 sejam seguidas ordenadamente. 


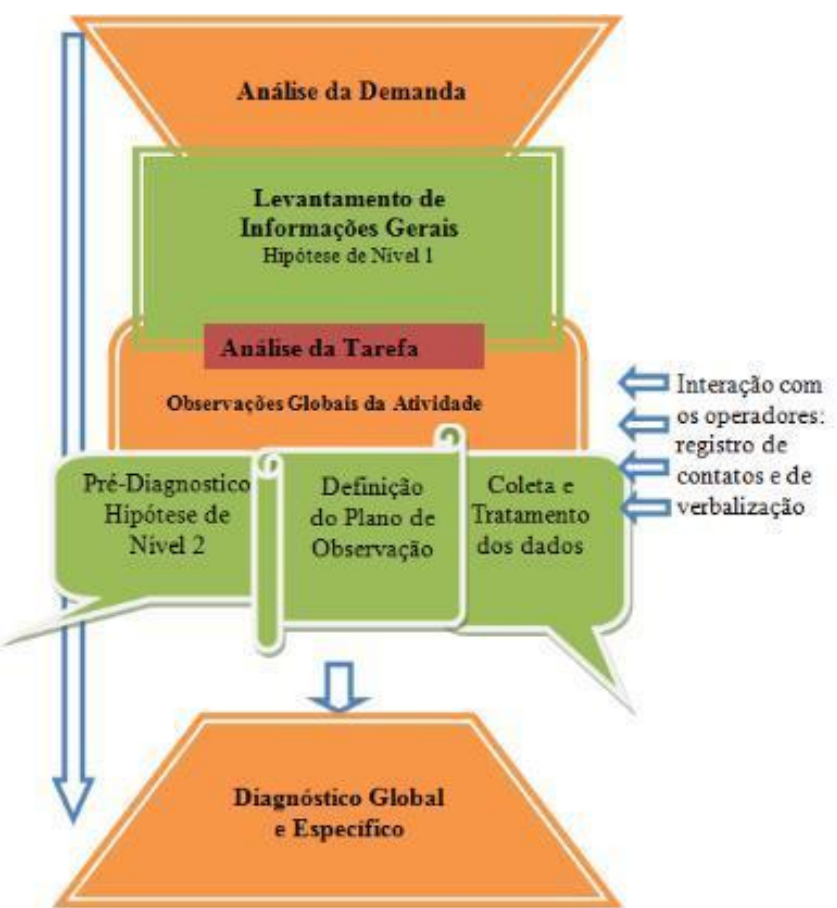

Figura 2 - Esquema geral da abordagem com as fases da AET. Fonte: Guérin et al. (2001).

No presente trabalho, o laboratório analisado tem como missão o estudo, desenvolvimento, otimização e inovação na tecnologia ambiental, aliada à proteção ambiental e à alta qualificação de recursos humanos.

O laboratório em questão visa a promover a ciência e tecnologia ambiental com o intuito de propiciar ganhos e diferenciais importantes para garantir qualidade de matérias-primas, de insumos químicos e produtos ambientalmente corretos, aumentar competitividade das empresas, com ênfase no desenvolvimento e emprego de tecnologias ambientalmente corretas.

As linhas de pesquisa do laboratório supracitado são: 1) Gestão ambiental e tecnologias limpas; 2) Tratamento de efluentes líquidos e resíduos sólidos; 3) Análises de emissões atmosféricas e de geração de gases; 4) Processos biotecnológicos.

Na pesquisa em tela, somente a última ênfase ou linha evidenciada acima será analisada, ou seja, a linha 4 (quatro).

\subsection{Sujeitos sob Observação da Pesquisa.}

O posto de trabalho analisado foi o de um laboratório que manipula ou faz a administração sistêmica de Nanopartículas (NPs), principalmente Nanotubos de Carbono, dosados por injeção intraperitoneal em peixes.

O processo de ensino e pesquisa é comandado pelos colaboradores: Professores do Programa de Pós-graduação em Engenharia, alunos de pós-graduação e da graduação, além de sete servidores Técnicos Administrativos em Educação (dois Engenheiros Químicos e cinco Técnicos de Laboratório). A seguir tem-se o Código Brasileiro de Ocupações - CBO dos diferentes tipos de usuários desse laboratório. 
Tem-se como Engenheiro Químico (CBO 2145-05), Engenheiro de desenvolvimento químico, Engenheiro de processamento químico, Engenheiro químico (alimentos e bebidas), Engenheiro químico de processos, Engenheiro químico de produção, Engenheiro químico de projetos, Engenheiro químico, em geral.

Descrição sumária da tarefa: Controlam processos químicos, físicos e biológicos, definindo parâmetros de controle, padrões, métodos analíticos e sistemas de amostragem. Desenvolvem processos e sistemas por meio de pesquisas, testes e simulação de processos e produtos. Projetam sistemas e equipamentos técnicos. Implantam sistemas de gestão ambiental e de segurança em processos e procedimentos de trabalho ao avaliar riscos, implantar e fiscalizar ações de controle. Coordenam equipes e atividades de trabalho. Elaboram documentação técnica de projetos, processos, sistemas e equipamentos desenvolvidos.

Pelo CBO, o Técnico de Laboratório (3011-05) é o Auxiliar de laboratorista (indústria), Laboratorista - exclusive análises clínicas, Laboratorista de ensaios mecânicos, Laboratorista de ensaios químicos, Laboratorista industrial, Laboratorista químico, Laboratorista têxtil, cuja descrição sumária é executarem ensaios físicos, químicos, metalográficos e biológicos. Garantirem a calibração dos equipamentos e realizarem amostragem de materiais. Trabalharem segundo normas de segurança, saúde e meio ambiente. Controlarem a qualidade. Participarem do sistema da qualidade da empresa/instituição e no desenvolvimento de novos produtos e fornecedores. Ainda, colaborarem no desenvolvimento de metodologias de análises.

\section{Apresentação e Análise dos Resultados.}

Esse item mostra os resultados do estudo de caso desenvolvido em um laboratório de uma Instituição Federal de Ensino Superior, abrangendo a análise ergonômica da demanda, tarefa e atividade. Utiliza-se para isso o método de AET de Guérin et al. (2001), técnica de observação livre ou direta conforme Gil (1999) e instrumento DEPARIS do autor Malchaire (2003).

\subsection{Análise Ergonômica da Demanda.}

Utilizou-se o instrumento descritivo e qualitativo de observação livre ou direta (in loco), preconizado por Gil (1999).

De acordo com os dados coletados, durante as visitas ao laboratório e posteriores estudos, verificou-se que a operação com o aparelho ou equipamento de maior importância para a AET é a do espectrofotômetro UV-Vis, por concentrar mais repetições de trabalho, atividades desordenadas e possibilidades de melhoria.

Identificaram-se, através de entrevistas diretas com todos os usuários, os pontos específicos que precisavam de inovações, por meio de sugestões colhidas junto aos colaboradores do posto analisado, buscando propostas de melhorias dos aspectos ergonômicos do posto de trabalho.

Com o intuito de alcançar o procedimento da Análise ergonômica da situação de trabalho (prescrito $=$ tarefa $\mathrm{x}$ real $=$ atividade), foi necessário ir a campo, utilizando para isso a técnica de observação livre ou direta (in loco).

O posto de trabalho está subordinado à Coordenadora do Laboratório e à Chefia do Departamento de Engenharia. Segundo Azevedo (2002), faz-se necessário, aliar decisões técnicas e administrativas a medidas educativas e informativas na formação de profissionais mais conscientes de sua atuação - atuação responsável - e participativos na gestão dessas questões (fluxograma abaixo). 


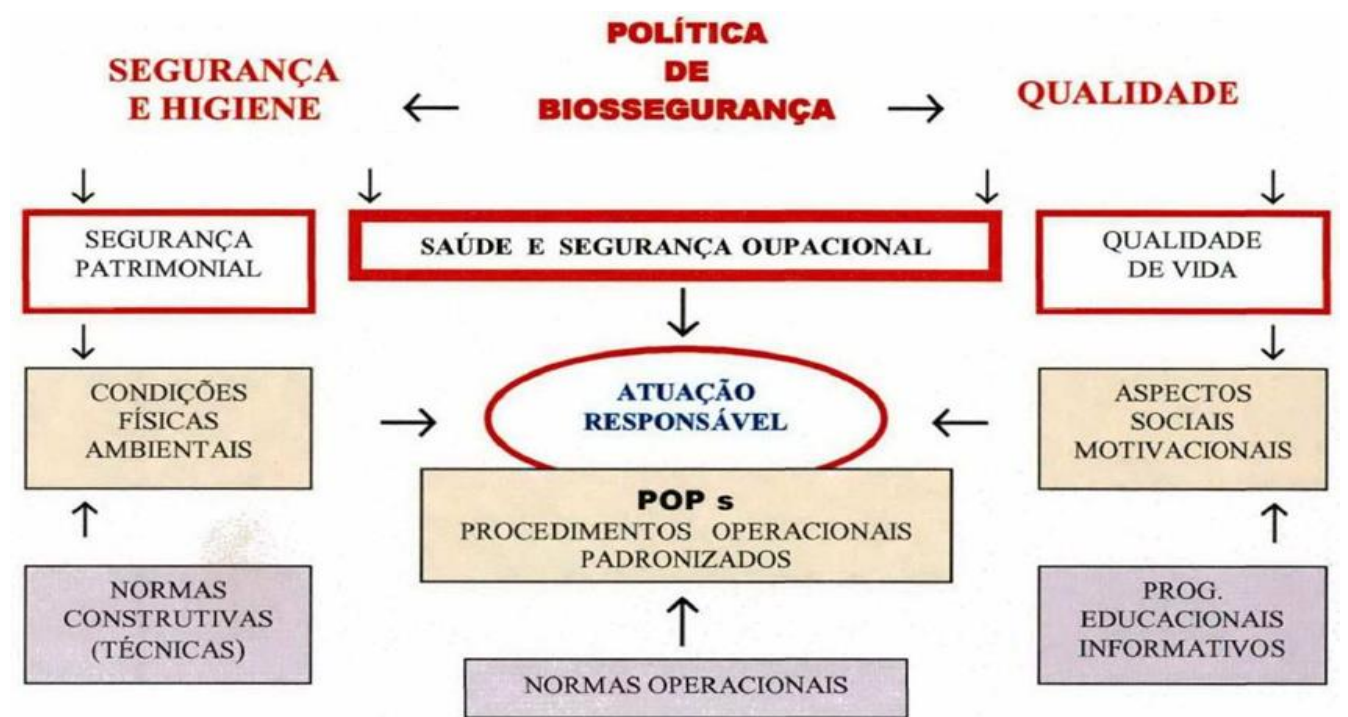

Figura 3 - Fluxograma da Política de Biossegurança de um laboratório. Fonte: Azevedo (2002).

As amostras e bioindicadores são destinados para diversas dissertações, teses e trabalho de conclusão de graduação. Ficam estocados em freezer, refrigerador ou incubadora até que a análise para essas pesquisas seja requerida com a aplicação de determinado método bioquímico.

Conforme o POP de segurança ou Ficha de Inspeção de Segurança de Produto Químico FISPQ, alguns cuidados habituais são necessários na manipulação dos reagentes do laboratório e quanto à estabilidade das suas condições operacionais. Reagentes não abertos e armazenados nas condições indicadas são estáveis até a data de expiração impressa no rótulo. Durante o manuseio, os reagentes estão sujeitos à contaminação de natureza química e microbiana, que podem provocar redução da estabilidade.

Pôde-se observar, ao fazer uma descrição sumária da infraestrutura do posto de trabalho (layout), que esse era constituído por duas áreas separadas por uma divisória. A primeira área desse laboratório realiza experiências ou ensaios físicos em escala piloto ou em nível de sistemas de bancada para preparação de corpo-de-prova e conta com: extrator Soxhlet, aparelhos para determinação de nitrogênio Kjeldhal, termobalança, máquina para ensaios de tração, incubadoras shaker, banho termostatizado, banho Dubnoff, capela de fluxo laminar, estufa a vácuo e mufla, cabine microbiológica, softímetros, espessímetros, equipamento de jar-test, balanças, entre outros equipamentos.

$\mathrm{Na}$ segunda área (analítica), o laboratório possui: titulador automático com Karl Fischer, espectrofotômetro UV-VIS, estereomicroscópio, cromatógrafo iônico, cromatógrafo gasoso, analisador de partículas e potencial zeta, analisador de carbono orgânico total (TOC) e nitrogênio para líquidos e sólidos, purificador de água ultra-pura, incubadora para DBO, sistema para análise de DQO, condutivímetro, colorímetro e outros equipamentos.

O laboratório de tecnologia ambiental conta também com o apoio da aparelhagem do laboratório Central Analítica e de equipamentos multiusuários do Departamento de Engenharia (Cromatógrafo HPLC, Termobalança, Cromatógrafo gasoso, analisador de umidade com infra-vermelho, Reômetro, entre outros), e de outros laboratórios.

\subsection{Análise da Tarefa.}


O objetivo principal do posto de trabalho é a realização de ensaios em espectrofotômetro ultravioleta visível (UV/VIS) duplo feixe com varredura marca PG Instruments modelo T80 de procedência inglesa capaz de medir com exatidão a absorbância em 505nm. Essas tarefas de medições são realizadas individualmente, ou seja, somente por um técnico por vez.

Assim, esse processo de medição é comandado por todos os técnicos de laboratório que fica em um banco alto, sem encosto, localizado à frente de um computador e controla esse equipamento de análise, por meio de teclado e mouse. O preenchimento das amostras é realizado em suporte motorizado para oito cubetas (em vidro, quartzo ou plástico) de dez milímetros e volume de 1,5 a $4,5 \mathrm{ml}$ e lâmpadas pré-alinhadas de tungstênio e deutério. $\mathrm{O}$ operador faz a troca da ponteira (consumível) do micropipetador (ferramenta) e seleciona o desligamento da lâmpada de deutério para aumentar sua vida útil. Esse técnico, também, faz a reposição das cubetas de prova quando se completa a análise.

Existem muitas queixas dos técnicos de laboratório quanto aos riscos, traços ou marcas nas cubetas de prova em material plástico, mesmo com o fabricante fornecendo esse consumível em embalagem de isopor.

Os POPs (Procedimentos Operacionais Padrão) destinam-se a descrever a magnitude da análise ou ensaio. A separação entre materiais e método/princípio é bem formulada, seguindo sistematicamente essa instrução. O laboratório não possui acreditação do Instituto Nacional de Metrologia, Qualidade e Tecnologia - INMETRO ou um certificado de Sistema de Gestão da Qualidade. As empresas de biotecnologia são responsáveis pela elaboração, revisão e aprovação do POP.

Quanto aos POPs, salienta-se que os parâmetros usados com frequência como indicadores gerais de estresse fisiológico em peixes, como glicose, glicogênio e lactato, podem estar alterados nos tecidos e sangue desses bioindicadores.

Um item que merece cuidado especial nos POPs é quanto ao uso e especificação mais detalhada de tipo do Equipamento de Proteção Individual e Coletiva - EPI/EPC. Os técnicos de laboratório utilizam guarda-pó, luva de procedimento e óculos de proteção.

Pode-se afirmar que ao técnico de laboratório cabe: ligar e desligar o computador e Espectrofotômetro UV/VIS quando julgar necessário; ficar atento ao aparecimento e à solução de problemas no laboratório; limpar por fora as cubetas, antes com papel macio e, por dentro com detergente, após seu uso na análise; avisar ao coordenador do laboratório quando esses consumíveis tiverem algum risco ou mancha.

Quanto à responsabilidade e iniciativa a ser tomada pelo técnico de laboratório, cabe trocar de posto ou revezamento das tarefas com outro técnico, quando considerar necessário. A frequência será determinada de acordo com as requisições de análises estipuladas pela chefia do Departamento de Engenharia ou coordenador do laboratório, respectivamente.

A periodicidade do trabalho ficará a cargo dos técnicos, fixando-se um tempo de análise mínima de trinta minutos. O técnico de laboratório não realiza nenhum ajuste sobre o equipamento, somente especifica se a absorbância terá varredura espectral, ou seja, o espectrofotômetro lerá a transmitância a cada comprimento de onda selecionado.

A duração do preenchimento do modulador de sinal ou suporte motorizado do espectrofotômetro (chopper com oito porta-amostras) é da ordem de 43 (quarenta e três) segundos, variando de acordo com as habilidades e ritmo de trabalho do técnico. Destaca-se a ocorrência de disparidade nos volumes das cubetas que podem interferir na análise da absorbância. 
Durante o período de férias dos cursos de Graduação, o Laboratório realiza uma seleção de bolsistas de iniciação científica e o Programa de Pós-Graduação em Engenharia faz a seleção de novos mestrandos e doutorandos. Faz-se assim, um recrutamento de novos colaboradores para o uso do equipamento de análise de dados para suas teses ou dissertações.

O colaborador recém-admitido, especificamente o técnico de laboratório, passa por um período de treinamento teórico de como operar o equipamento (capacitação), para depois passar para o aprendizado prático em laboratório de pequenas quantidades de análises.

Assim, o técnico já capacitado é liberado para trabalhar a plena carga e a realizar operações de grandes quantidades de análises. O período mínimo é de três semanas de adaptação, antes de utilizar todo o potencial do trabalhador recentemente admitido ou que tenha se ausentado do trabalho por período longo.

Quanto à formação do técnico atual do posto de trabalho, pode-se afirmar que, por operar um equipamento que constantemente é solicitado, apresenta-se com uma boa habilidade e ritmo para a realização da tarefa, pois esse já está acostumado com o processo de análise em questão.

Utilizou-se a técnica de observação livre ou direta conforme Gil (1999) para aporte (obtenção) de dados referentes às condições ambientais, tais como:

\subsubsection{Condições físicas e fisiológicas do trabalho.}

O horário de início das atividades no laboratório começa às 8h. Caso não haja uma operação imediata do espectrofotômetro do laboratório, os técnicos e engenheiros ficam à disposição do coordenador e chefia. Esses profissionais que trabalham no local desenvolvem uma carga horária de oito horas diárias, com intervalo de uma hora. Às $12 \mathrm{~h}$, há uma pausa geral do laboratório para o almoço. Os colaboradores retornam dessa pausa às $13 \mathrm{~h}$.

O expediente do laboratório encerra-se às $17 \mathrm{~h}$, com exceções para postos de trabalho que necessitem realizar serviço extraordinário, em função da produção de artigos ou da realização de experimentos. Tal atividade ocorre esporadicamente, de acordo com a determinação da chefia do Departamento de Engenharia.

\subsubsection{Medidas ambientais.}

O prédio onde se encontra o laboratório possui grandes dimensões em relação ao posto de trabalho. Esse local possui dois corredores, o primeiro para as máquinas e o segundo para os equipamentos de análises que recebem os reagentes e vidrarias do laboratório. Na extremidade desses corredores existem duas portas duplas nas aberturas.

As paredes são de alvenaria e possuem acabamento interno com pintura branca no reboco. O teto possui forro em PVC branco, distribuído uniformemente. No mesmo prédio, além do laboratório analisado, encontram-se, também, outros laboratórios de pesquisa do Departamento de Engenharia.

\subsubsection{Temperatura (clima de trabalho).}

O laboratório localiza-se dentro de um pavilhão de dimensões 26x28m. A temperatura do laboratório, tanto no inverno quanto no verão, é praticamente igual a desse pavilhão. O prédio apresenta portões de carga e descarga em suas aberturas que estão sempre fechadas devido à segurança patrimonial. Isso impossibilita que o ar externo circule constantemente pelo pavilhão. Não existe nenhum equipamento que forneça calor aos técnicos na operação dos equipamentos de análise. 
O laboratório conta com ar condicionado de potência 18000 e 36000 btus e com desumidificadores que controlam a umidade do ar adicionando ou retirando água do ambiente, respectivamente.

Para fins de conforto térmico, a avaliação pericial pode utilizar as condições definidas pela Norma Regulamentadora NR17 - Ergonomia, que em seu subitem 17.5.2 alínea "b" estabelece o Índice de temperatura Efetiva entre 20 a $23^{\circ} \mathrm{C}$, medido na altura do tórax do trabalhador. A umidade relativa do ar não será inferior a $40 \%$.

O técnico de segurança do trabalho da instituição utiliza para monitoramento um instrumento de medição termômetro globo marca DP Union modelo TGD-200, devidamente calibrado e com as baterias carregadas.

\subsubsection{Iluminação ambiental e artificial (localizada).}

A iluminação do prédio é realizada por iluminação natural (janelas de vidro) e por iluminação artificial (luminárias com lâmpadas fluorescentes). O técnico de segurança do trabalho da instituição mediu essa intensidade com luxímetro digital marca Lux Tester modelo YF-1065 e verificou que a iluminação do laboratório com lâmpadas fluorescentes atende à NBR 5413.

As medições ou monitoramentos do iluminamento foram realizados no campo de trabalho ou a $0,75 \mathrm{~m}$ do chão. Esse equipamento estava calibrado e foi aferido antes das medições.

Em dias de pouca luminosidade, o posto de trabalho fica com intensidade de iluminação também suficiente, podendo a incidência da luz natural ser regulada com uso de persianas horizontais.

\subsubsection{Substâncias químicas.}

O posto de trabalho apresenta, em um dia de trabalho intenso, uma grande concentração de resíduos sólidos e líquidos. Conforme o POP, a Azina Sódica é tóxica e deve-se tomar cuidado evitando a ingestão. No contato com os olhos, lavar imediatamente com grande quantidade de água ou soro fisiológico e procurando auxílio médico.

Como o laboratório da instituição trabalha com produtos solventes tóxicos, principalmente nos rotaevaporadores, torna-se obrigatório aos técnicos o uso de capela e máscara de proteção com cartucho. Verificou-se que os técnicos de laboratório e os engenheiros não têm como hábito a utilização de máscaras de proteção, o que pode ser prejudicial à saúde desses.

Durante as visitas ao posto de trabalho, verificou-se a existência de grande quantidade de resíduos acumulados ao redor do laboratório, esperando o recolhimento ou retirada pelo Centro de Gestão e Tratamento de Resíduos Químicos. Esses passivos gerados no âmbito da instituição devem ter as embalagens (bombonas de cinco litros) devidamente identificadas e rotuladas conforme Portaria 9816 de 15 de dezembro de 2015 da reitoria.

As capelas de fluxo horizontal-laminar de ar são equipamentos de proteção, que reduzem a propagação de substâncias químicas no ambiente pela ventilação e exaustão, as quais evitam que o técnico respire esses produtos poluentes. A regular manutenção tem importância para evitar o saturamento de filtros e bloqueio de tubulação de chaminé.

\subsection{Análise Ergonômica das Atividades de Trabalho.}


A Análise Ergonômica do Trabalho (AET) é útil para o estudo dos riscos (químicos, físicos, ergonômicos e de acidentes) e a discrepância entre o prescrito nos POPs e o trabalho real (atividades) efetuado pelos Técnicos de Laboratório quando realizam a análise no Espectrofotômetro UV/VIS e equipamentos correlatos (balanças, pipetadores, rotaevaporadores, entre outros).

Essa tarefa deve ser redesenhada para atendimento de demandas de ampliação da instituição que incorporará novos cursos voltados para o campo da Engenharia Bioquímica.

Deve-se considerar os riscos pela falta de consumíveis (reagentes e vidrarias)/acessórios/ferramentas/equipamento e espaço adequado à necessidade dos técnicos de laboratório.

A apresentação da tarefa é feita oralmente, conforme citado anteriormente, apresentando-se aos técnicos de laboratório todas as instruções e macetes necessários para uma boa execução das atividades subsequentes.

Inicialmente, todas essas instruções serão dadas diariamente e, logo que a coordenadora do laboratório considere que o técnico está pronto para a realização do trabalho, esse passará a receber instruções semanalmente e, se necessário, mensalmente. Caso haja uma troca de solução de produto químico ou bioindicador ou equipamento / alocação do técnico de laboratório, esse deverá receber novamente as instruções devidas para a realização da nova tarefa.

O grau de precisão da atividade não varia de acordo com a habilidade de operação do equipamento de laboratório pelo técnico e sim de acordo com o conhecimento em métodos analíticos. A balança analítica tem uma resolução metrológica de quatro casas após a vírgula, calibrada para indicar a diferença de pesos existentes entre o estipulado e o medido, por exemplo, para confecção de soluções químicas (misturas homogêneas de duas ou mais substâncias).

Assim, dependendo do grau de exigência do coordenador, o técnico de laboratório poderá ter acesso aos manuais de operação dos equipamentos. Esse segundo comentário é muito válido e está sendo muito utilizado em Instituições que têm problemas de deslocamento de pessoal para manutenção de equipamentos, pois o técnico de laboratório, com esse tipo de instrução, poderá realizar além do seu trabalho específico uma manutenção autônoma, ou seja, ficaria responsável pela operação e por pequenos reparos no equipamento.

Tanto os engenheiros, quanto os técnicos de laboratório têm livre iniciativa para realizarem qualquer tarefa que diga respeito ao seu posto de trabalho, seguindo o que foi previamente determinado pelo coordenador. Os técnicos de laboratório não têm permissão de atuarem em outros laboratórios de pesquisa que não a deles, com exceção se solicitados pela Chefia ou Direção do Departamento de Engenharia.

Foram analisados dois Procedimentos Operacionais Padrão (POPs) elaborados por empresa que fornece kits de Lactato e Glicose. Descreve-se assim, os ensaios/análises das amostras a serem efetuados no laboratório. Verifica-se a elaboração desses documentos do ponto de vista metodológico com a prescrição da tarefa de cada ensaio/análise.

\subsection{Verbalizações e Atividades (Análise da Tarefa).}

Identificou-se com o diagnóstico DEPARIS, de que maneira o trabalho é executado e como se desenvolve com a participação dos usuários (Técnicos e Engenheiros). O responsável pelo controle 
das análises e da produção de artigos do laboratório é a Coordenadora e/ou Chefia do Departamento de Engenharia. Os técnicos de laboratório opinaram acerca do conforto/alcance e riscos do trabalho.

Pode-se dizer que a coordenadora faz um controle secundário das requisições de análise, pois quem faz o controle primário, ou seja, o controle dos resultados de artigos é o técnico de laboratório.

Os Técnicos de Laboratório identificaram um layout inadequado para realizar as experiências e análises. Entre outros, a inapropriada localização do rotaevaporador que deveria estar dentro da capela desse laboratório.

Questionou-se sobre a eficácia do sistema de compras por empenho ou dispensa de licitação. Não existe um profissional de compras e as requisições de vidraria e reagentes são realizadas pelos próprios técnicos de laboratório. Não há uma programação anual de verbas para esses consumíveis e orçamentos para manutenção. Esses materiais são estocados em pequenos almoxarifados de forma desorganizada. Isso gera insatisfação geral dos técnicos.

Com relação ao mobiliário, identificaram-se problemas como a elevada altura de bancadas para os computadores. Essas bancadas de trabalho possuem prateleiras e não possuem portas para acomodar ou guardar relatórios, ferramentas e equipamentos.

Quanto aos riscos de acidentes, destacaram queimaduras, choque elétrico e possibilidade de incêndio devido aos produtos químicos estocados no laboratório. Existe também a preocupação com asfixia devido aos gases especiais de equipamentos de cromatografia. As janelas de ventilação são muito altas e esse laboratório não apresenta monitor de qualidade de ar.

Quanto a movimentos repetitivos, citaram insatisfação com pipetas volumétricas manuais. Essa ferramenta causa desconforto na mão (dedos) e punho do técnico.

Os técnicos verbalizaram a preocupação com acúmulo de resíduos químicos sólidos e líquidos e indagaram sobre a falta de pesquisa sobre clima e qualidade de vida no trabalho desse laboratório. Os trabalhadores ressaltam que recebem um plano de saúde em nível nacional.

Risco biológico também foi identificado pelos colaboradores como fonte de insatisfação em suas atividades. Por se tratar de um laboratório de tecnologia ambiental, esses profissionais recebem insalubridade de grau máximo.

\subsection{Diagnóstico e Recomendações e Análise Participativa - DEPARIS.}

A seguir, pode-se observar registro fotográfico (duas imagens): pipetagem no posto de trabalho e do laboratório em questão. 

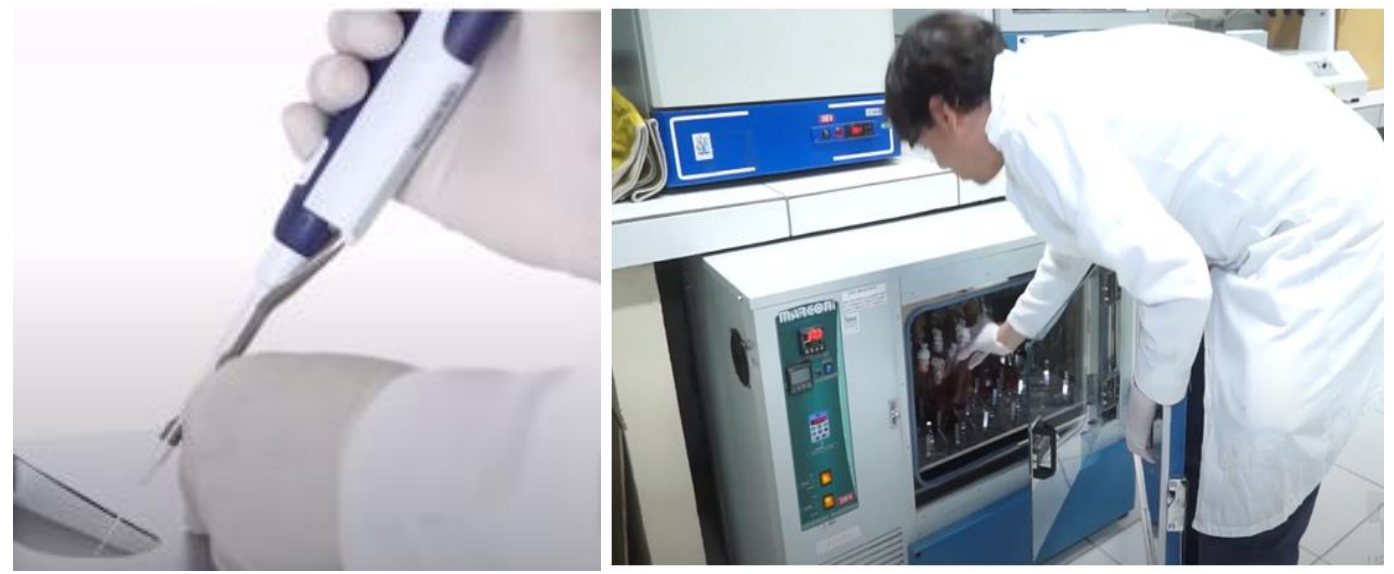

Figuras 4 e 5 - Pipetagem e Laboratório da Instituição de Ensino Superior analisado. Fonte: Autor (2016).

Assim, com relação ao laboratório analisado, verificam-se os seguintes dados / índices:

\section{1 - As zonas de trabalho (satisfatório)}

O laboratório demanda a incorporação de novos cursos voltados ao campo da Engenharia. A ampliação do layout ou espaço do ambiente do posto de trabalho poderia aumentar o espaço para acomodação das máquinas e equipamentos de análises. $\mathrm{O}$ aumento de área solucionaria na distribuição dos chuveiros de emergência e lava-olhos (ao menos dois por corredor) e extintores de incêndio.

A legislação NBR16291 de 05/2014 trata dos requisitos gerais para chuveiros e lava-olhos de emergência. Deve-se respeitar a distância mínima requerida entre esses para garantia da segurança dos Técnicos de Laboratório. Assim, teria-se um local fixo, sinalizado e sem obstruções desses sistemas de proteção. Ressalta-se que a legislação ABNT 12.693 trata dos Sistemas de Proteção por extintores de Incêndios.

Os extintores devem ser colocados obedecendo à distância máxima a ser percorrida para se atingir "um" extintor (varia de dez a vinte e cinco metros) e devem ser instalados a não mais de cinco metros da porta de entrada.

\section{2 - A organização técnica entre os postos (satisfatório)}

As requisições de análises foram reorganizadas e sistematizadas por email, fixando-se assim, as prioridades por equipamento disponível.

\section{3 - Os locais de trabalho (insatisfatório)}

No posto analisado, o assento apresentou problemas, por não possuir regulagem vertical. A regulagem horizontal deixou muito a desejar e o encosto do assento não demonstrou condições ergonômicas adequadas para uma correta postura do técnico de laboratório, ou seja, ao se posicionar em relação ao aparelho ou equipamento UV-Vis, esse técnico geralmente sentava com a coluna em rotação lateral e flexão anterior (ALEXANDRE, 2013).

\section{4 - Os riscos de acidentes (insatisfatório)}

Falta treinamento em Segurança em Instalações e Serviços em Eletricidade - NR10, exaustão forçada e monitor de qualidade de ar do laboratório.

Os extintores de incêndio são adequados e periodicamente vistoriados e recarregados. 


\section{5 - Os comandos e sinais (satisfatório)}

Os instrumentos e equipamentos de análise do posto apresentam comandos e sinais para eficaz tomada de informações e cores vivas facilitam a suas localizações com segurança e mínimo esforço e fadiga com conforto aos técnicos de laboratório.

\section{6 - As ferramentas e os materiais de trabalho (satisfatório)}

Os colaboradores do posto de trabalho têm a responsabilidade de verificar o bom funcionamento de todos os instrumentos e equipamentos de análises que compõem o posto e ainda de comunicar qualquer falha ao coordenador do laboratório, que providencia orçamento para a manutenção terceirizada desses equipamentos.

Poderia ser feito um estudo no mercado, para verificar se há algum tipo de cubeta com menos riscos e traços para diminuir as perdas desse consumível por descarte sem uso nas análises do laboratório.

\section{7 - O trabalho repetitivo (satisfatório)}

O trabalho consiste no uso de teclado, mouse e preenchimento das cubetas de prova. Verificouse que o ritmo de trabalho do técnico de laboratório não era muito intenso e desgastante. Esse fato é amenizado pelo motivo das tarefas serem revezadas de tempos em tempos pelos colaboradores.

\section{8 - Os manuseios ou levantamentos de carga (satisfatório)}

O técnico de laboratório não necessitava de um maior esforço físico para a realização de suas atividades, somente apresentava esforços físicos decorrentes da constante variação da postura para as medições das análises. Necessitava apenas realizar o transporte de algumas ferramentas e pesadas bombas de vácuo. Sugere-se a organização de revezamentos entre os técnicos e a troca de mobília por assento com regulagem horizontal e vertical para suavizar o desconforto no posto de trabalho.

\section{9 - A carga mental (satisfatório)}

O técnico, com o tempo, não desenvolve um estado de fadiga mental e física. Existe grande necessidade de o técnico de laboratório variar a postura para realizar as medições.

Sugere-se novamente a quebra de rotina e o revezamento. Melhora-se assim, as condições de trabalho e o interesse dos técnicos.

\section{0 - A iluminação (satisfatório)}

A iluminação presente no posto de trabalho dos técnicos de laboratório, apresenta-se satisfatória ao nível da realização da tarefa. O técnico de segurança do trabalho monitorou o ambiente do posto de trabalho com aparelho luxímetro modelo digital marca Lux Tester modelo YF-1065. As luminárias garantem excelente nível de iluminação, ou seja, todas as medições foram superiores a 300 lux, atendendo à exigência da NBR 5413.

As persianas evitam a incidência direta de luz sobre as bancadas. As luzes de emergência do laboratório estavam todas estragadas (com as baterias descarregadas).

\section{1 - O ruído (intermediário)}

Com relação ao ruído, notou-se que os técnicos de laboratório não usam protetores auriculares. Existe um nobrake ou estabilizador que emite ruído constante e esporadicamente é usado um aparelho sonicador. O técnico de segurança do trabalho da instituição efetuou medições superiores ao limite de tolerância de $50 \mathrm{~dB}(\mathrm{~A})$, ou seja, acima do limite máximo de ruído que pode provocar perturbações 
na atividade ou tipo de trabalho rotineiro de laboratórios e salas de aula estabelecido pela NBR 10152/1987 - Níveis de ruído para conforto acústico.

Isso pode causar efeitos sobre o sistema auditivo e nervoso dos laboratoristas, como: mudança temporária do limiar de audição (incômodo), fadiga, irritação e perturbação na comunicação (dificuldades emocionais e mentais). Para melhora da situação, sugere-se reduzir o ruído na fonte e recobrir o nobrake com material de parede absorvente.

Os níveis de ruído contínuo e intermitente foram medidos em decibéis (dBA), com o medidor operando no circuito de compensação A e circuito de resposta lenta $(S L O W)$. O equipamento utilizado na coleta de dados foi um audiodosímetro (Noise Logging Analyser) marca Quest, tipo 2 modelo Q300 calibrado e aferido antes das medições.

As medições de ruído foram realizadas na altura do ouvido do servidor, conforme determina a Lei 6514/78 da Portaria 3214 NR-15 anexos 1 e 2.

\section{2 - Os ambientes térmicos (satisfatório)}

Nos dias de chuva sugere-se ligar os desumidificadores.

\section{3 - Os riscos químicos e biológicos (intermediário)}

A instituição fornece Equipamentos de Proteção Individual - EPI's como guarda-pós, máscaras e óculos protetores que deveriam ser usados pelos técnicos, devido ao risco químico como ácidos e solventes e poeiras em suspensão, que se encontram no posto de trabalho. Porém, isso geralmente não era seguido pelos servidores do laboratório. Esses devem estar atentos para evitar acidentes, principalmente quando da troca de funções (flexibilização). Existem cartazes indicativos visíveis salientando o uso obrigatório desses equipamentos. A instituição disponibiliza armário individual para cada servidor, onde esse possa guardar seus equipamentos de forma organizada.

Sugere-se a criação de um local fora do laboratório analisado para descarte de óleo mineral das bombas de vácuo e para a armazenagem e preparo do material de cromatografia (reagentes e vidrarias).

\section{4 - As vibrações (satisfatório)}

Para a rubrica vibrações no posto de trabalho avaliado, não se percebeu significância nesse fator ambiental.

\section{5 - As relações de trabalho entre trabalhadores (satisfatório)}

Pode-se verificar que as relações entre os técnicos são bem amistosas, uma vez que possuíam certa liberdade para realizar as funções do posto de trabalho (delegação de responsabilidades entre titulares do posto) e decidem de comum acordo de quanto em quanto tempo será feito o revezamento das tarefas.

\section{6 - O ambiente social local e geral (intermediário)}

O posto de trabalho analisado é formado por apenas um servidor, mas o laboratório tem uma equipe com 07 (sete) colaboradores, uma vez que para que o trabalho seja realizado satisfatoriamente, devem trabalhar em equipe, pois a função de Técnico e Engenheiro depende uma da outra.

Os banheiros são limpos de forma regular, mas necessitam de conserto para assegurar melhor operacionalidade.

\section{7 - O conteúdo do trabalho (intermediário)}


Todos os trabalhadores do posto podem realizar todas as tarefas e todos podem colaborar nos setups ou trocas de ferramenta (micropipetador).

A duração de adaptação do colaborador recém-admitido, especificamente a capacitação do técnico de laboratório, tem duração de três semanas. As análises não necessitam de retrabalho por erros de medição, apenas algumas são feitas em triplicata.

Isso torna o posto de trabalho em nível intermediário, da rubrica de conteúdo de trabalho, de acordo com a avaliação técnica feita pelo técnico de segurança de trabalho da instituição.

\section{8 - O ambiente psicossocial (intermediário)}

Os técnicos estão subordinados diretamente à Coordenadora do Laboratório. Essa última, periodicamente verifica o andamento do trabalho e se está dentro do determinado pelo Departamento de Engenharia, principalmente, quanto ao controle das requisições de análises.

Em comparação com outros postos de trabalho da instituição, o posto analisado apresenta certas vantagens, como ser um trabalho que exige pouco esforço físico, não ser muito monótono, devido à troca repetida de função entre os servidores técnicos de laboratório. Não falta pessoal quando um servidor fica doente e durante as férias.

A falta de pesquisa sobre clima e qualidade de vida no trabalho desse laboratório, seriam os aspectos a estudar com um maior detalhamento.

\section{Considerações Finais.}

O levantamento da AET do posto de trabalho dos técnicos de laboratório é imprescindível para a caracterização da SST, porém há escassez de dados para Ergotoxicologia reportados na literatura. O método Guérin et al. (2001) recomenda a elaboração de uma Cartilha de Recomendações. Sugerese a confecção de um Caderno de Sugestões de Melhorias para o Laboratório da Instituição.

Ao aplicar o método de diagnóstico participativo de riscos (DEPARIS), elucidou-se o fluxo de análises de pesquisa biotecnológica que é realizada no laboratório em questão. Avaliaram-se a relação entre o tamanho de planos do posto de trabalho e possíveis riscos para postura e movimentos.

As prescrições são determinadas resumidamente nos POPs. É necessário incluir um Diagrama de fluxo simples para que os passos sejam melhor interpretados. Permite-se assim, a eficiência na explicitação desses passos para ações prescritas e, consequentemente, a padronização da tarefa.

As ações ergonômicas permitem ao laboratório um maior entendimento dos modos de funcionamento interno (coerência nas atividades), refletindo no avanço de conceito do Programa de Pós-Graduação stricto sensu (Mestrado e Doutorado) inserido na Coordenação de Aperfeiçoamento de Pessoal de Nível Superior - Capes, Fundação do Ministério da Educação - MEC.

Como sugestão para trabalhos futuros, sugere-se a identificação (análise ou caracterização) das lacunas de conhecimento existentes entre a empresa/instituição e trabalhadores em um Posto de Trabalho com Nanotecnologia (lacunas sobre os mecanismos toxicológicos das nanopartículas em geral e em especial dos nanotubos de carbono). Sugere-se também, uma nova avaliação com estudo detalhado do uso de equipamentos e ferramentas de trabalho para uma análise mais eficaz dos movimentos e esforços da tarefa. Sugere-se ainda, a aplicação de ferramentas de controle de risco com nanomateriais. Na literatura encontram-se várias abordagens (ANDRADE \& AMARAL, 2012; HÖCK et al., 2012; OSTIGUY et al., 2008; PAIK et al., 2008; entre outras). 
Este estudo buscou demonstrar a importância de tratar a questão ergonômica, em nível estratégico. Com um ambiente em condições de trabalho favoráveis, pode-se reduzir o absenteísmo laboral dos técnicos administrativos em educação, aumentando a produtividade na confecção de artigos e publicação de periódicos de pesquisa, com ênfase em meio ambiente, e de teses e dissertações. Garante-se, assim, a fundamentação nos pilares da Instituição: Ensino, Pesquisa e Extensão.

\section{Referências.}

ABERGO - Associação Brasileira de Ergonomia, 2000. O que é Ergonomia. Disponível em: < http://www.abergo.org.br/internas.php?pg=o_que_e_ergonomia\#/>. Acesso em: 25 de agosto de 2020.

ABRAHÃO, Júlia et al. Introdução à Ergonomia. Da Prática à Teoria. São Paulo: Blucher, 2009.

AHN, J. J.; KIM, Y.; CORLEY, E. A. \& SCHEUFELE, D. A. Laboratory Safety and Nanotechnology Workers: an Analysis of Current Guidelines in the USA. Nanoethics, Phoenix, jul. 2015.

ALEXANDRE, Marcia Augusta B. Condições de trabalho e desordens musculoesqueléticas relacionadas à coluna vertebral em dentistas. Dissertação (Mestrado em Engenharia de Produção), Universidade Federal do Rio Grande do Sul, Porto Alegre, 2013.

AMARAL, Fernando G. Leitura de artigos - Metodologia de Intervenção Ergonômica. Disponível em: <http://www.producao.ufrgs.br/arquivos/disciplinas/385_metodologia_aet_imp.pdf>. Acesso em: 25 de agosto de 2020 .

ANDRADE, L. R. B. Sistemática de ações de segurança e saúde no trabalho para laboratórios de pesquisa de nanotecnologia. Tese (Doutorado em Engenharia de Produção). Universidade Federal do Rio Grande do Sul, Porto Alegre, 2013, 257f.

ARCURI, A. S. A. \& PONTES, J. M. Nanotecnologia e seus Impactos na Saúde, Meio Ambiente e no Mundo do Trabalho. In: Sonia Corina Hess. (Org.). Ensaios sobre Poluição e Doenças no Brasil. 1ed. São Paulo: Outras Expressões. v. 1, p. 315-336, 2018.

AZEVEDO, Maria de Fátima Mendes. Análise de Riscos em Ambientes Laboratoriais Clínicos: Uma abordagem centrada em Biossegurança e Ergonomia. Dissertação (Mestrado em Engenharia de Produção). Universidade Federal de Santa Catarina, Florianópolis, 2002.

BALBINOTTI, Giles. A Ergonomia como Princípio e Prática nas Empresas. Curitiba: Gênesis, 2003.

BARNES, Ralph Mosser. Estudo de Movimentos e de Tempos: Projeto e Medida do Trabalho. 6. ed. São Paulo: Blucher, 1999.

BAZZO, W. A. \& PEREIRA, L. T. V. Introdução à Engenharia. 2. ed. Florianópolis: UFSC, 1990.

BERTOLETTI, Eduardo. Determinação da Ecotoxicidade Crônica para Danio Rerio. J. Braz. Soc. Ecotoxicol., v.4, n. 1-3, 2009.

BOLIS, Ivan. Contribuições da ergonomia para a melhoria do trabalho e para o processo de emancipação dos sujeitos. Dissertação (Mestrado em Engenharia de Produção). Universidade de São Paulo, São Paulo, 2011. 
BROWN, V. K. Predictive acute toxicity test with pesticides. Acta Pharmacologica et Toxicológica, v.52, n.2, p.247-261, 1983.

BURMANN, Laura Sanz. Condições de Saúde e Segurança em Laboratórios de Ensaios de Materiais Elétricos: Uma Ferramenta de Análise. Dissertação (Mestrado em Engenharia de Produção). Universidade Federal do Rio Grande do Sul, Porto Alegre, 2008.

COUTO, Hudson de Araújo. Ergonomia aplicada ao Trabalho: Manual Técnico da Máquina Humana. V. 1. Belo Horizonte: Ergo, 1995.

CRANDALL, Beth et al. Working Minds: A Practitioner's Guide to Cognitive Task Analysis. Massachusetts: MIT, 2006.

CUNHA, Cristiane Paim. Avaliação da Segurança e saúde do Trabalho (SST) na Atividade de serraria no município de Cerro Grande do Sul. Dissertação (Mestrado em Avaliação de Impactos Ambientais). Universidade La Salle, Canoas, 2013, $105 f$.

DUL, J. \& WEERDMEESTER, B. Ergonomia Prática. 3. ed. São Paulo: Blucher, 2012.

FALZON, Pierre. Ergonomia. São Paulo: Blucher, 2007.

FISCHER, Frida Marina. Tópicos de Saúde do Trabalhador. São Paulo: Hucitec, 1989.

FRANÇA, Ana Cristina Limonge. Qualidade de Vida no Trabalho (QVT): Conceitos e Práticas nas Empresas da Sociedade Pós-Industrial. São Paulo: Atlas, 2004.

GIL, Antônio Carlos. Métodos e Técnicas de Pesquisa Social. 5. ed. Porto Alegre: Atlas, 1999.

GRANDJEAN, Etienne et al. Manual de Ergonomia: Adaptando o Trabalho ao Homem. 5. ed. Porto Alegre: Bookman, 2005.

GUÉRIN, François et al. Compreender o Trabalho para Transformá-lo: A prática da Ergonomia. São Paulo: Blucher, 2001.

GUIMARÃES, Lia Buarque de Macedo. Ergonomia de Processo: Histórico, Ambiente, Segurança. 5. ed. V. 1. Porto Alegre: FEENG/UFRGS, 2004.

Ergonomia de Processo: Macroergonomia, Organização do Trabalho. 5ed. V. 2. Porto Alegre: FEENG/UFRGS, 2006.

HELANDER, Martin. A Guide to the Ergonomics of Manufacturing. London: Taylor e Francis, 1995.

HÖCK, J. et al. Guidelines on the Precautionary Matrix for Synthetic Nanomaterials. Federal Office of Public Health and Federal Office for the Environment, Version 2.1, Berne, 2011.

IIDA, Itiro. Ergonomia Projeto e Produção. 2. ed. São Paulo: Blucher, 2005.

LAVILLE, Antoine. Ergonomia. São Paulo: EPU. Universidade de São Paulo, 1977.

LIGEIRO, Joellen. Ferramentas de Avaliação Ergonômica em Atividades Multifuncionais: A contribuição da ergonomia para o Design de Ambientes de Trabalho. Dissertação (Mestrado em Design). Universidade Estadual Paulista Julio de Mesquita Filho-UNESP, Bauru, 2010.

MAGAlHÃES, D. P. \& FERRÃO FILHO, A. S. A Ecotoxicologia como ferramenta no biomonitoramento de ecossistemas aquáticos. OECOL. Bras. v. 12, n. 3, p. 355-381, 2008. 
MAINIERI, Osmar Martins \& HISSA, Maria da Glória. Vida e Ambiente. Rio de Janeiro: Petrobrás; Brasília: SENAI/DN, 2002.

MALCHAIRE, J. Stratégie SOBANE et méthode de Pépistage DEPARIS, série stratégie SOBANE: Gestion des risques professionels, SPF Emploi, Travail et concertation Sociale. 2003.

MASCULO, Francisco Soares et al. Ergonomia: Trabalho Adequado e Eficiente. Rio de Janeiro: ABEPRO, 2011.

MENDES, René. Patologia do Trabalho. Rio de Janeiro: Atheneu, 1995.

MENTE, Felipe José. Modelo Ergonômico de Gestão Participativa em Segurança e Saúde Ocupacional. Dissertação (Mestrado em Engenharia de Produção). Universidade Federal do Rio Grande do Sul, Porto Alegre, 2007.

MINISTÉRIO DO TRABALHO E EMPREGO-MTE. CBO-Classificação Brasileira de Ocupações. Disponível em http://www.mte.gov.br. Acessada em 17/10/2017.

MINISTÉRIO DO TRABALHO E EMPREGO-MTE. Manual de Aplicação da Norma Regulamentadora No 17.2. ed. Brasília: MTE, SIT, 2002.

MORAES, Ana Maria de et al. Ergonomia: Conceitos e Aplicações. 2. ed. Teresópolis: 2AB, 2012.

MUTHER, Richard. Planejamento do layout: Sistema SLP. São Paulo: Edgard Blücher, 1978.

NICOLA, Alessandro Danielli et al. O uso da informação como instrumento de auxílio à gestão da saúde e segurança no trabalho: análise de publicações em SST no Brasil. III Workshop Gestão Integrada: Risco e Sustentabilidade. São Paulo: SENAC, 2007.

OSTIGUY, C. et al. Health Effects of Nanoparticles. IRSST, R-589. Montréal, 2008.

PAHL, G \& BEITZ, W. Engineering Design: a systematic approach. Londres: Springer Verlag, 1992.

PALMER, Colin. Ergonomia. Rio de Janeiro: Editora da Fundação Getúlio Vargas, 1976.

PAVANI, Ronildo Aparecido. Estudo ergonômico aplicando o método Occupational Repetitive Actions (OCRA): uma contribuição para gestão da saúde do trabalho. Dissertação (Mestrado em Gestão Integrada em Saúde do Trabalho e Meio Ambiente). Serviço Nacional do Comércio-SENAC, São Paulo, 2007.

RAMAZZINI, Bernardino. As Doenças dos Trabalhadores. São Paulo: FUNDACENTRO, 1999.

RAND, Gary M. Fundamentals of Aquatic Toxicology: Effects, Environmental Fate, and Risk Assessment. 2. ed. Nova York: CRC, 1995.

RIO, R. \& PIRES, L. Ergonomia: Fundamentos da Prática Ergonômica. 3. ed. São Paulo: LTr, 2001.

SALVENDY, Gavriel. Handbook of Human Factors and Ergonomics. 3. ed. West Lafayette, Indiana: John Wiley \& Sons, 2006.

SANTOS, N. \& FIALHO, F. Manual de Análise Ergonômica no Trabalho. 2. ed. Curitiba: Gênesis, 1997.

SCHREINER, F. R; ALLGAYER, R. \& AMARAL, F. G. Avaliação Ergonômica Participativa em Situações de Concepção e Reprojeto - O Caso de um Laboratório de Microbiologia Molecular. XXVIII Encontro Nacional de Engenharia de Produção. Rio de Janeiro, 2008. 
SCHULTE, P. A. \& SALAMANCA-BUENTELLO, F. Ethical and scientific issues of nanotechnology in the workplace. Environ Health Perspectiv, n. 115, p. 5-12, San Francisco, jan. 2007.

SERVIÇO SOCIAL DA INDÚSTRIA Legislação Comentada: NR 17 - Ergonomia. Salvador: FIEB / SESI Bahia, 2008.

TORREIRA, Raul Peragallo. Manual de Segurança Industrial - Legislação Nacional e Internacional. São Paulo: Margus, 1999.

VERDUSSEN, Roberto. Ergonomia: a Racionalização Humanizada do Trabalho. Rio de Janeiro: Livros técnicos e científicos, 1978.

VERGARA, Lizandra G. L.; SCHAPPO, Andre; SPEROTTO, Gustavo R. \& ALVES, Bruno V. Análise Ergonômica do Trabalho de um Operador de Dobradeira de uma Metalúrgica. XXXVI Encontro Nacional de Engenharia de Produção. João Pessoa, 2016.

VIDAL, Mário Cezar R. Ergonomia na empresa: útil, prática e aplicada, 2. ed. Rio de Janeiro: Virtual Científica, 2002.

VIEIRA, Sebastião Ivone. Manual de Saúde e Segurança do Trabalho. Florianópolis: Mestra, 2000.

WISNER, Alain. Por dentro do trabalho: Ergonomia Método e Técnica. São Paulo: FTD / Oboré, 1987. 